\title{
The Impact of Technology Platform Change on the Information Seeking Behavior of Academicians in Amhara
}

\author{
Chalachew Muluken Liyew, Bahir Dar University Institute of Technology, Bahir Dar, Ethiopia \\ Sertse Abebe Ayalew, Bahir Dar University Institute of Technology, Bahir Dar, Ethiopia \\ Yibeltal Tafere Bayih, Bahir Dar University Institute of Technology, Bahir Dar, Ethiopia
}

\begin{abstract}
This study empirically measures the information seeking behavior of academician on the rapid technology platform change environment in the technology institutes found in Amhara Region, Ethiopia. The questionnaire was prepared and distributed to the academicians of technology institutes to collect information about the medium which was used for seeking information. The questions were how devices helped to seek information, the purpose of the information, and challenges faced while seeking information and measure of satisfaction level for the digital library in the institutes. Hence, the study reveals that users used portable devices to seek information from the internet and the digital library rather than using printed copies of information for their academic, research and community service activities. The results show that the information dissemination medium should be changed to electronic information due to the rapid growth of information and communication technology that impacts the information seeking behavior of users, and provide continuous support and training to use the electronic resources.
\end{abstract}

\section{KEYWORDS}

Academicians, Information Seeking, Information Seeking Behavior, Technology

\section{INTRODUCTION}

When an individual needs information, the information does not come to him/ her on its own. Rather, the individual must search for and seek the information. According to Kumar (1990) "information seeking behavior is mainly concerned with who needs what kind of information for what reasons; how information is found, evaluated and used." Wilson (1999) also defines information behavior as activities of an individual engaged in identifying his or her need, searching and using or transferring the information.

Information is a key element for academicians (i.e. academic faculty and researchers) for their teaching and learning, research, community problem solving and innovative activities. Academicians need to search information to acquire the required knowledge and skill to contribute in the development 
of the respective nation. Nowadays, more and more information are available for information seekers in different format of electronic resources (e-journals, online databases and digital libraries) in the web and print-based resources in the library (Kadli \& Kumbar, 2011).

Information and communication technology affect the academic library service exchange system. According to Sujatha (2016) the information available on the web has affected the seekers behavior to search electronic information in the library. Hence, libraries should respond to the change of the information and communication technology that has effects on the seeking behavior of academicians. Wang, et al. (2007) showed that the growth of information and communication technology shifted the search and access operation of academicians from the traditional service to the modern internetbased information access role.

The information needs and access methods of the academicians in the technology institute found in the Amhara region, Ethiopia have been changed due to the rapid growth of information and communication technology. Understanding the information seeking behavior of academicians in the technology institute of the Amhara Region in Ethiopia on the rapid change of technology environment is an important research topic to propose effective and efficient information system, library collection, services and facilities. Therefore, the main objective of this study was to measure empirically the information seeking behavior of academicians on the rapid growth of ICT platform environment in the region.

\section{LITERATURE REVIEW}

Nui and Hemminger (2011) conducted research on the factors that affect the information seeking behavior of academicians and identified that demographic, psychological, role-related, and environmental factors (department types and library distance) affected the information seeking behavior of the academicians. In addition, Kumari et al., (2013) reported that a maximum number of teachers used the library to access books, use periodicals, journals and reference material for different purposes. The researcher added that maximum number of teachers never used audio-visual material as the source of information. However, these studies could not explore the effect of information and communication technology on the information seeking behavior of the academics' environment.

Mohamed (2007) carried out a research on the use of ICT-based resources and services in special libraries in Kerala. The study concluded that ICT-based resources and services were highly significant for academic and research work. However, the orientation and training on the use of ICT to seek resources was inadequate.

Niu et al. (2010) conducted a survey on academic researchers in natural science, engineering, and medical science from five research universities in the United States to understand different aspects of researcher's information-seeking behavior. The findings showed that electronic resources were used the most to search and access academic content so that the academic libraries should support the needs of scientists.

The use of electronic devices, networks and different information formats are changing information access operations worldwide. Kadli and Kumbar (2011), and Ellis and Haugan (1997) discuss that books, journals and articles are available on the internet in digitized form for quicker and better information access for academicians in the ICT era. According to Bhattacharjee and Sinha (2016), before the advent of the ICT era, information searching and access took huge amounts of time because a large volume of information had been stored in non-electronic or analog form. The change to ICT has helped to increase the productivity of researchers, authors and academicians. Nowadays, academicians are in a position to provide updated information in their publications, facilitating teaching-learning activities with this information and doing community services by identifying community problems easily.

In an empirical study on the impact of information technology on the information-seeking behavior of users Manikandan et al. (2013) revealed that a majority of the participants confirmed that the 
computer, telecommunications and its facilities, the internet and digitalization were very useful for the users' information seeking in the electronic environment. Kadli and Kumbar (2013), and Esew et al. (2014) discussed that the internet has tremendous influences on the information seeking behavior of academics and Mahmod and Saeed (2014) added that most of the academics used computers to seek digital information so that information should be digitized for the academics.

The study conducted in Ethiopia at Jimma University on undergraduate student information seeking behavior (Tilahun \& Natarajan, 2016) concluded that students preferred to use the internet and e-resources for information purposes and that the students were satisfied with the services. However, several challenges were faced, including electric power fluctuation and low internet speed for downloading documents. This study did not show the information seeking behavior of academicians in Jimma University.

\section{METHODOLOGY}

To gather the data crucial for this survey study, academicians of the technology institutes found in Amhara region universities of Ethiopia were considered. The researchers believed that the institute of technology academicians were highly responsive to the changes of technology that helps to seek information. The questionnaires were distributed to 378 academicians. $309(81.75 \%)$ of the academicians responded to the questionnaires. The collected data was analyzed and interpreted using simple mathematical calculations.

\section{DATA ANALYSIS}

The academicians were asked how frequently they used the internet to seek information. It is clear in Table 1 that nearly all (99.4\%) of the respondents used the internet daily to seek the information. Hence, the technology institute academicians used internet to search and gather the information they need.

The report showed that most of the academicians (98.4\%) used Mobile phones to search information followed by laptop (97.7\%), desktop (69.2\%) and palmtop (33.0\%) (Table 3). Hence, most of the academicians used mobile technology wherever they go due to its portability and internet availability where ever they went.

Table 2 shows that most of the respondents (86.4\%) are using the library occasionally. About $5.8 \%$ respondents are visiting the library monthly, $3.2 \%$ of the respondents never use, $2.9 \%$ of the respondents weekly and $1.6 \%$ of the respondents use the library daily. Consequently, most of the academicians used the library occasionally due to elapsing time in using Internet as depicted in Table 1 and other academic tasks.

Table 1. frequency of using internet

\begin{tabular}{|l|l|l|}
\hline \multicolumn{1}{|c|}{ Frequency of use Internet } & \multicolumn{1}{c|}{ Respondents } & \multicolumn{1}{c|}{ Response } \\
\hline Daily & 307 & $99.4 \%$ \\
\hline Weekly & 2 & $0.6 \%$ \\
\hline Monthly & - & - \\
\hline Quarterly & - & - \\
\hline Annually & - & - \\
\hline Never & - & - \\
\hline Total & 309 & $100 \%$ \\
\hline
\end{tabular}


Table 2. Frequency of using university library

\begin{tabular}{|l|l|l|}
\hline \multicolumn{1}{|c|}{ Frequency of Visit } & \multicolumn{1}{c|}{ Respondents } & \multicolumn{1}{c|}{ Response } \\
\hline Daily & 5 & $1.6 \%$ \\
\hline Weekly & 9 & $2.9 \%$ \\
\hline Monthly & 18 & $5.8 \%$ \\
\hline Occasionally & 267 & $86.4 \%$ \\
\hline Never & 10 & $3.2 \%$ \\
\hline Total & 309 & $100 \%$ \\
\hline
\end{tabular}

Table 3. Devices used to search information on the internet

\begin{tabular}{|l|l|l|}
\hline \multicolumn{1}{|c|}{ Devices } & \multicolumn{1}{c|}{ Respondents } & \multicolumn{1}{c|}{ Response } \\
\hline Laptop & 302 & $97.7 \%$ \\
\hline Desktop & 214 & $69.2 \%$ \\
\hline Palmtop & 102 & $33.0 \%$ \\
\hline Mobile & 304 & $98.4 \%$ \\
\hline
\end{tabular}

Note: multiple option selection allowed.

A question about what challenges the academicians faced while seeking information using their devices were asked. Table 4 shows that most respondents (99.3\%) faced electric problems followed by $95.1 \%$ of respondents facing a challenge of a slow network, $75.1 \%$ of respondents faced time delays in accessing the required information. File incompatibility challenge is not a problem faced by the academicians.

The data in Table 5 shows that most of the respondents (93.5\%) indicated that the purpose of seeking information was for preparing for class lectures, $68.9 \%$ for research work, $75.7 \%$ for writing and presenting papers, $66.3 \%$ for updating their knowledge, $64.1 \%$ for the Ph.D. study, $16.8 \%$ for entertainment and $11.0 \%$ for guiding researchers. Hence, most of the respondents seek information for preparing class lecture notes as it might be expected.

The academicians were asked whether they were satisfied or not using the digital library services in their institute. Table 6 shows that $45.6 \%$ of the respondents reported that the digital library was not established in their institute, so they did not get digital library services at their institute. 36.9\% of the respondents reported that even if there were digital library services at their institute, they were not satisfied by the service it delivered, followed by $17.5 \%$ of the respondents that were satisfied by the services it delivers.

Table 4. Challenges faced using devices

\begin{tabular}{|l|l|l|}
\hline \multicolumn{1}{|c|}{ Challenges } & \multicolumn{1}{c|}{ Respondents } & \multicolumn{1}{c|}{ Response } \\
\hline File incompatible with device & 0 & 0 \\
\hline $\begin{array}{l}\text { Long time spend to get required } \\
\text { information }\end{array}$ & 232 & $75.1 \%$ \\
\hline Networks are too slow & 294 & $95.1 \%$ \\
\hline Electric is being on and off frequently & 307 & $99.3 \%$ \\
\hline
\end{tabular}

Note: multiple option selection was allowed 
Table 5. Purpose of seeking the information

\begin{tabular}{|l|l|l|}
\hline \multicolumn{1}{|c|}{ Purpose } & \multicolumn{1}{c|}{ Respondents } & \multicolumn{1}{c|}{ Response } \\
\hline For preparing class lecture & 289 & $93.5 \%$ \\
\hline For doing research work & 213 & $68.9 \%$ \\
\hline For doing Ph.D. & 198 & $64.1 \%$ \\
\hline For entertainment & 52 & $16.8 \%$ \\
\hline For updating knowledge & 205 & $66.3 \%$ \\
\hline For writing and presenting paper & 234 & $75.7 \%$ \\
\hline For guiding researchers & 34 & $11.0 \%$ \\
\hline
\end{tabular}

Note: multiple option selection was allowed

Table 6. Satisfaction of users by digital library services

\begin{tabular}{|l|l|l|}
\hline \multicolumn{1}{|c|}{ Satisfy Using Digital Library } & \multicolumn{1}{c|}{ Respondents } & \multicolumn{1}{c|}{ Response } \\
\hline Satisfied & 54 & $17.5 \%$ \\
\hline Not satisfied & 114 & $36.9 \%$ \\
\hline digital library is not established & 141 & $45.6 \%$ \\
\hline
\end{tabular}

To identify resources of information for academicians and how frequently these resources were used, participants were asked how often they used books, journals, preprints, personal communication, webpages, and online databases and attended at conference and conference proceedings. The primary resources for their academic activities are webpages (99.4\%), books (92.2\%), and personal communications $(88.7 \%$ ) which are used in daily basis as showed in the Table 7 . Moreover, the academicians attend conference and use conference proceedings annually and never, online databases

Table 7. Resource used for academic activities

\begin{tabular}{|c|c|c|c|c|c|c|}
\hline Resources & Never & Annually & Quarterly & Monthly & Weekly & Daily \\
\hline Books & - & - & - & $\begin{array}{l}9 \\
2.9 \%\end{array}$ & $\begin{array}{l}15 \\
4.9 \%\end{array}$ & $\begin{array}{l}285 \\
92.2 \%\end{array}$ \\
\hline Journals & $\begin{array}{l}146 \\
47.2 \%\end{array}$ & - & - & $\begin{array}{l}24 \\
7.8 \%\end{array}$ & $\begin{array}{l}67 \\
21.7 \%\end{array}$ & $\begin{array}{l}72 \\
23.3 \%\end{array}$ \\
\hline Preprints & $\begin{array}{l}309 \\
100 \%\end{array}$ & - & - & - & - & - \\
\hline $\begin{array}{l}\text { Attendance at } \\
\text { conference }\end{array}$ & $\begin{array}{l}18 \\
5.8 \%\end{array}$ & $\begin{array}{l}291 \\
94.2 \%\end{array}$ & - & - & - & - \\
\hline $\begin{array}{l}\text { Conference } \\
\text { proceedings }\end{array}$ & $\begin{array}{l}26 \\
8.4 \%\end{array}$ & $\begin{array}{l}283 \\
91.6 \%\end{array}$ & - & - & - & - \\
\hline Webpages & - & - & - & - & $\begin{array}{l}2 \\
0.6 \%\end{array}$ & $\begin{array}{l}307 \\
99.4 \%\end{array}$ \\
\hline $\begin{array}{l}\text { Personal } \\
\text { Communication }\end{array}$ & - & - & $\begin{array}{l}3 \\
1.0 \%\end{array}$ & $\begin{array}{l}6 \\
1.9 \%\end{array}$ & $\begin{array}{l}26 \\
8.4 \%\end{array}$ & $\begin{array}{l}274 \\
88.7 \%\end{array}$ \\
\hline $\begin{array}{l}\text { Online } \\
\text { Databases }\end{array}$ & $\begin{array}{l}11 \\
3.6 \%\end{array}$ & $\begin{array}{l}78 \\
25.2 \%\end{array}$ & $\begin{array}{l}171 \\
55.3 \%\end{array}$ & - & $\begin{array}{l}49 \\
15.9 \%\end{array}$ & - \\
\hline
\end{tabular}


quarterly and never used preprints. Hence, most of the academicians are confidently responding that the webpages are primarily used information resources.

The next question asked of academicians is what challenges were faced while using their institute's digital library to seek information. 168 (54.4\%) respondents had opportunities using their digital libraries as depicted in the Table 8 . Out of the 168 respondents $166(98.8 \%)$ reported that they did not get support from librarians even if the service was offered, followed by $121(72.0 \%)$ who faced internet connection problem to use the service, then $62(36.9 \%)$ faced how to use the service problem and did not get the required materials from the digital library and the technology that the academicians used that supports the materials in the digital library.

The academicians use google.com (93.2\%) followed by 6.8\% yahoo.com frequently to search for and gather information on the internet (Table 9).

\section{FINDINGS}

The main objective of this study was to measure the information seeking behavior of academicians on the rapid growth of ICT platform environment in Amhara region. Consequently, the research findings are summarized below.

Almost all of the academicians seek information on the internet daily (99.1\%) using portable devices such as mobile tablets and phones (98.4\%) followed by laptops $(97.7 \%)$. However, most of the academicians responded that they visited the library occasionally $(86.4 \%)$ followed by monthly (5.8\%). The challenges faced by the academicians while seeking information on the internet using portable devices were frequent fluctuation of electric power supply (99.3\%) and slow network connections $(95.1 \%)$.

The academicians search and gather information for the purpose of lecture notes preparation (93.5\%), writing and presenting reports (75.7\%) and doing research works (68.9\%). Almost all of the academicians used websites (99.4\%), books (92.2\%) and personal communication (88.7\%) as their primary resources.

Table 8. Challenges using digital library services

\begin{tabular}{|l|l|l|}
\hline \multicolumn{1}{|c|}{ Challenges } & \multicolumn{1}{c|}{ Respondents } & \multicolumn{1}{c|}{ Response } \\
\hline Don't know how to use it & 62 & $36.9 \%$ \\
\hline No support how to use it & 166 & $98.8 \%$ \\
\hline Internet connection & 121 & $72.0 \%$ \\
\hline Can't find required material & 62 & $36.9 \%$ \\
\hline Technology incompatibility & - & - \\
\hline
\end{tabular}

Note: multiple option selection allowed

Table 9. Frequently used search engine

\begin{tabular}{|l|l|l|}
\hline \multicolumn{1}{|c|}{ Search Engine } & \multicolumn{1}{c|}{ Respondents } & \multicolumn{1}{c|}{ Response } \\
\hline Google.com & 288 & $93.2 \%$ \\
\hline Yahoo.com & 21 & $6.8 \%$ \\
\hline msn.com & - & - \\
\hline Alta Vista.com & - & - \\
\hline Others & - & - \\
\hline
\end{tabular}


Less than half of the study participants (45.6\%) revealed that a digital library was not available at their institutes. Moreover, those participants that have access to digital libraries replied that they were not satisfied (36.9\%) with the existing services in their institutes while only $17.5 \%$ of them were satisfied with the services delivered by the digital libraries at their institutes.

The challenges faced the academicians while using their institute digital library were: inability to get proper support on how to use it from the librarians (98.8\%), internet connection problem (72.0\%) and lack of awareness and inability to find the required materials (36.9\%). Moreover, most of the study participants frequently used Google (93.2\%) and Yahoo (6.8\%) search engines.

\section{DISCUSSION}

Most of the academicians included in this study used the internet to search and gather information on daily (99.4\%) basis using electronic devices such as mobile tablets/phones (98.4\%) followed by laptops (97.7\%) and desktops (69.2\%). These results showed that the rapid advancements of technology shifted the academicians' use of desktops at the office to mobile devices to seek information from the internet. Similarly, the study conducted at Jimma University, Ethiopia on undergraduate students (Tilahun and Natarajan, 2016) revealed that most of the students' spent time using internet at the library, and due to this reason they visited the library daily. However, Kumar (2013) found that 10\% of social science research scholars did not use the internet because they had no basic knowledge about the internet and its importance. One can conclude that technology-focused academicians are more responsive to ever changing technology than social science research scholars.

The previous work of Kumar (2013) showed that $50 \%$ of the respondents used the library daily. However, Sujatha (2016) showed that $76.1 \%$ respondents visited the library whenever necessary and no respondents replied that they visited the library every day due to time constraint. Similarly, this study showed that $86.4 \%$ of academicians visited the library occasionally and $1.6 \%$ did not at all. Hence, most academicians preferred using internet daily than using the library to seek information for academic purposes.

Even though $54.4 \%$ of the academicians have used the digital library at the institute, most of them $(36.9 \%)$ were not satisfied with the digital library services due to several challenges. Some of the challenges they faced were an inability to get support and training from the librarian (98.8\%), not knowing how to use the digital library resources, a slow internet connection $(72.0 \%)$, and an inability to get up-to-date and required information on the digital library (36.9\%). Hence, to motivate academicians to use the digital library, the librarians should provide continuous support and training to increase the academicians' knowledge of how to use the digital library. The librarians should provide up-to-date information that helps the academicians for teaching and learning, research and community service.

Since the job of academicians is teaching/learning, research and community service, their purpose of seeking information should be in line with the expected job. To assure this the academicians were asked the purpose of information seeking. Most of the academicians (93.5\%) responded that for preparing class lecture, $(75.7 \%)$ for writing and presenting paper and $68.9 \%$ for doing research.

The academicians used search engines to search information. The search engines used by academicians most frequently were google.com (93.2\%) followed by yahoo.com (6.8\%). The challenges the academicians faced while using electronic devices to search were electric power being off and on frequently which resulted the internet being off and on. Similar work Tilahun and Natarajan (2016) found that students faced electric power fluctuation and slow network connection challenges at Jimma University, Ethiopia. Moreover, they faced a slow internet connection so that accessing required information took too long. Hence, the institutes should provide alternative electric power source like solar power or generator and it is better to upgrade the bandwidth of the internet to enhance its speed to fulfill users' interest. 


\section{CONCLUSION}

The advancement of technology has been changing the day-to-day activities of people. It has been transforming and revolutionizing the works of academicians too. According to the results of this study, technology platform changes have significantly impacted the information seeking behavior of academicians. For instance, academicians have been shifting from the non-portable desktop computer to portable devices such as laptop computers and mobile phones for seeking information for their day-to-day academic activities.

The wider coverage of internet connectivity has provided better opportunities for academicians to seek information anywhere at any time. As findings of this study supported, most academicians prefer to use digital or electronic resources on the internet for various academic activities rather than traditional library resources.

The transformation of academicians in their need for electronic resources via digital libraries rather than traditional libraries is leading technology institutes to establish digital libraries. However, in order to establish a reliable digital library system that satisfies majority of academicians, availability of electronic resources, ICT infrastructure, and proper support and training are pre-conditions that technology institutions should be working to fulfill the demands of academicians. 


\section{REFERENCES}

Bhattacharjee, S., \& Sinha, M. K. (2016). Models of Information Seeking Behaviour: An Overview. Asian Journal of Multidisciplinary Studies, 4(5), 266-268.

Ellis, D., \& Haugan, M. (1997). Modelling the information seeking patterns of engineers and research scientists in an industrial environment. The Journal of Documentation, 53(4), $384-403$. doi:10.1108/EUM0000000007204

Esew, M., Makarfi,A., Goshie, R. W., \& Jimada, A. (2014). An Overview of Users Information Seeking Behaviour on Online Resources. IOSR Journal Of Humanities And Social Science, 19(1), 9-17.

Kadli, J. H., \& Kumbar, B. D. (2011). Faculty Information-Seeking Behaviour in the Changing ICT Environment: A study of commerce colleges in Mumbai.

Kadli, J. H., \& Kumbar, B. D. (2013). Library resources, services and information seeking behaviour in changing ICT environment: a literature review. Library Philosophy and Practice.

Kumar, A. (2013). Assessing the information need and information seeking behavior of research scholars of MBPG College: A case study. International Journal of Digital Library Services, 3(3), 1-12.

Kumar, G. (1990). Defining the Concept of Information Need. Social Science Information: Problem and Prospectus. new Delhi: Vikas Publishing.

Kumari, S., Kumari, S., \& Davi, S. (2013). A Study of Information Needs and Information Seeking Behaviour of Teachers of NIT, Kurukshetra, India. Educationia Confab, 2(6), 64-68.

Mahmod, A., \& Saeed, A. (2014). To Study the Impact of Digital Information Seeking Behaviour of Research Fellows in Private Universities of Karachi. International Journal of Humanities and Social Science Invention, 3(12), 1-8.

Manikandan, G., Esmail, S. M., \& Nagarajan, M. (2013). Impact of Information Technology on Information Seeking Behavior of the Users: An Empirical Study. Journal of Advances in Library and Information Science, $1(2), 60-64$.

Mohamed, H. K. (2007). Use of ICT based resources and services in special libraries in Kerala. Annals of library and Information studies, 54(1), 23-31.

Niu, X., Hemminger, B. M., Lown, C., Adams, S., Brown, C., Level, A., \& Cataldo, T. (2010). National Study of Information Seeking Behavior of Academic Researchers in the United States. Journal of the American Society for Information Science and Technology, 61(5), 869-890. doi:10.1002/asi.21307

Nui, X., \& Hemminger, B. M. (2011). A Study of Factors That Affect the Information-Seeking Behavior of Academic Scientists. Journal of the American Society for Information Science and Technology, 1-18.

Sujatha, S. (2016). Exploring information seeking behaviour in the changing ict environment: A snapshot of Kakatiya University faculty. International Journal of Information Services and Technology, 11-15.

Tilahun, E., \& Natarajan, M. (2016). Information seeking behavior of Undergraduate students of Agriculture and Veterinary Medicine of Jimma University. Journal of Library and Information Science, $6(2), 349-366$.

Wang, P., Dervos, D. A., Zhang, Y., \& Wu, L. (2007). Information-seeking behaviors of academic researchers in the Internet Age: A user study in the United States, China and Greece. Proceedings of the Association for Information Science and Technology, 44(1), 1-29.

Wilson, T. D. (1999). Models in Information Behaviour Research. The Journal of Documentation, 55(3), $249-270$. doi:10.1108/EUM0000000007145 
Chalachew Muluken Liyew received his MSc in Information Technology at the University of Gondar in 2015. He was appointed as a lecturer at Bahir Dar University Institute of Technology in Computing Faculty. He has done research entitled: "Faxed/photocopied image document retrieval:Pre-processing" Now, he is a lecturer and working on Digital Library system developer and administrator at Bahir Dar University Institute of Technology.

Sertse Abebe Ayalew has a BSc and MSc degree in information science from Addis Ababa University, Ethiopia. He is currently a lecturer at Bahir Dar University.

Yibeltal Tafere Bayih is a lecturer at Bahir Dar University, Bahir Dar Institute of Technology, Faculty of Computing. He has an International master's in digital library Learning for Oslo University college, Norway, Tallinn University Estonia and Parma University, Italy. He also has an MSc in computer science from Addis Ababa University, Ethiopia. He has 15 years of experience in teaching and research. 